\title{
Supplementary phages for the investigation of strains of methicillin-resistant Staphylococcus aureus
}

\author{
JUDITH F. RICHARDSON, NUANCHAN CHITTASOBHON* and R. R. MARPLES \\ Division of Hospital Infection, Central Public Health Laboratory, 61, Colindale Avenue, London NW9 5HT and \\ - Department of Microbiology, Faculty of Medicine, Khon Kaen University, Khon Kaen 40002, Thailand
}

\begin{abstract}
Summary. Nineteen experimental phages were derived by mitomycin-C induction from methicillin-resistant strains of Staphylococcus aureus collected world-wide. They were assessed for their ability to distinguish isolates of a methicillin-resistant strain of $S$. aureus epidemic in the London area from other British strains, both sensitive and resistant to methicillin. The experimental phages were most active against strains of phage groups III and I+ III. One phage was related to the phages of lytic group I. A typing pattern common to isolates of the epidemic strain was identified and used as an aid in the recognition of this strain. Ten of the phages were retained for further study.
\end{abstract}

\section{Introduction}

Towards the end of 1982 it became apparent that a methicillin-resistant strain of Staphylococcus aureus had become epidemic in the London area. (Marples and Cooke, 1985; Ayliffe et al., 1986; Marples et al., 1986). Subsequently this strain spread throughout the Thames Regions (National Health Service administrative divisions) and occasional isolates, usually associated with patient movement, were received from other Regions. This epidemic strain belonged to phage group III, and although usually untypable at routine test dilution (RTD), was sometimes lysed strongly by phage 84 of the international set. At 100RTD the strain was lysed weakly by phage 85 , and usually strongly by two reserve, non-specific phages, 88A and 932, used at the Central Public Health Laboratory, London.

This paper describes the extraction of phages from other methicillin-resistant strains of $S$. aureus isolated throughout the world and the evaluation of this phage set as an aid to the recognition of isolates of the Thames epidemic methicillin-resistant $S$. aureus (EMRSA).

\section{Materials and methods}

\section{S. aureus strains}

In response to a request sent to the national phage typing centres, 577 isolates of methicillin-resistant $S$. aureus were received from 27 countries. To help elucidate how many distinct strains had been included in the

Received 9 Feb. 1987; accepted 13 Apr. 1987. isolates received from each country, phage carried by all isolates from a country was spotted on to all other isolates from that country. A representative isolate ST84/5518, of the Thames EMRSA was included in every experiment. From these results, a pair of strains, one phage producing, and one lysed by that phage, was sought from each set of isolates received. Twenty-four pairs of strains were selected. In two cases a suitable "propagating strain" could not be found from within the set of isolates submitted from the same country as the phage-producing strain, so strains isolated in the UK were used. The initial selection process included equal numbers of potential phages which lysed, or did not lyse, the representative isolate of the Thames EMRSA strain.

\section{Phage propagation}

Free phage was produced by mitomycin $\mathrm{C}$ induction of the phage-producing isolate (de Saxe and Notley, 1978). The induced culture was centrifuged to remove most bacterial cells and the phage-containing supernate sterilised by filtration through a $0.45-\mu \mathrm{m}$ Gelman filter. This phage suspension was then titrated on to the phagesensitive propagating strain. Adaptation of the phage to this strain was continued through three single-plaque passages; the phage was then propagated to high titre in broth culture (Blair and Williams, 1961) or by the soft agar overlay method of Swanstrom and Adams (1951). No attempt was made to minimise host modification.

Phages propagated to at least 100 times routine test dilution (100 RTD) and their propagating strains were given, for convenience, the next numbers in a departmental reference collection, e.g., CRF 616 and CRF 616PS; the phage and its propagating strain were then lyophilised, for long-term storage. Short-term storage was at $4^{\circ} \mathrm{C}$. The stability of the phage at this temperature was assessed by sequential titrations during a 6-month period. 
The serological group and lytic spectrum (host range) of these phages were determined (Rippon, 1956).

\section{Phage typing}

The resulting phage set was tested against 547 unselected methicillin-sensitive strains of $S$. aureus received for routine phage typing over a 4-week period, 160 isolates of the Thames EMRSA, and 213 other methicillin-resistant strains of $S$. aureus from centres throughout the British Isles.

Phage typing was performed by standard methods; the phages were tested at RTD only (Blair and Williams, 1961). The purpose of this investigation was to develop a phage set to distinguish isolates of one particular strain of S. aureus, the Thames EMRSA, from isolates of similar strains; these new phages were, therefore, tested only against strains from centres in Britain. The results were assessed partly by inspection and partly by the use of a data analysis program on a microcomputer.

\section{Results}

\section{Development of phage set}

Nineteen phages were propagated to a sufficiently high titre to be included in this trial (tables I and
II). These phages included phage 85 of the international set of $S$. aureus typing phages propagated on strain ST84/5518, an isolate of the Thames EMRSA. The adapted phage was CRF 616. Also included were two phages, CRF 617 and CRF 624, derived from the prophage carried by the Thames strain propagated on two other distinct strains, NCTC 8325 and 1030. The phage from strain ST84/ 5518 was serological group $F$, and had a limited host range-6/7/31/47/85. It underwent modification in both propagating strains. Phage 617 , the phage resulting from growth of this prophage in strain NCTC 8325, which carries three prophages (Novick, 1967) and has at least two modification systems (Iordanescu and Surdeanu, 1976), was of serological group B and had an increased host range (table II). Phage 624, the phage resulting from growth of the same prophage in strain 1030, an apparently prophage-free strain (Novick 1967), was of serological group $\mathrm{F}$ but had a considerably reduced host range (strain $83 \mathrm{~A}$ only) in comparison with the original prophage. Phage CRF 628, which also was propagated on strain 1030 , showed a reduced host range compared with the other phages.

Table I. Sources and characteristics of experimental phages

\begin{tabular}{|c|c|c|c|c|c|c|c|}
\hline \multirow{2}{*}{$\begin{array}{l}\text { CRF } \\
\text { no. }\end{array}$} & \multirow{2}{*}{$\begin{array}{l}\text { Phage-producing } \\
\text { strain (phage group) }\end{array}$} & \multirow{2}{*}{$\begin{array}{c}\text { Propagating } \\
\text { strain } \dagger \text { (phage group) }\end{array}$} & \multirow[b]{2}{*}{ RTD } & \multicolumn{3}{|c|}{ Country of Origin } & \multirow[b]{2}{*}{ Stability $\ddagger$} \\
\hline & & & & phage & \multicolumn{2}{|c|}{ propagating strain } & \\
\hline 616 & PH 85 & ST84/5518 (III) & $10^{-4}$ & $*$ & & UK & good \\
\hline 617 & ST84/5518 (III) & NCTC 8325 (III) & $10^{-4}$ & UK & & $47^{*}$ & good \\
\hline 618 & ST85/1749 (NT) & ST $85 / 1758$ (III) & $10^{-4}$ & \multirow{3}{*}{\multicolumn{3}{|c|}{$\begin{array}{l}\text { Hungary } \\
\text { East Germany } \\
\text { Israel }\end{array}$}} & good \\
\hline 619 & ST85/3902 (III) & ST85/3906 (III) & $5 \times 10^{-3}$ & & & & poor \\
\hline 620 & ST85/4550 (III) & ST85/4548 (III) & $5 \times 10^{-3}$ & & & & good \\
\hline 621 & ST85/5496 (NT) & ST85/5485 (III) & $10^{-5}$ & \multirow{4}{*}{\multicolumn{3}{|c|}{$\begin{array}{c}\text { Saudi Arabia } \\
\text { Iraq } \\
\text { Belgium } \\
\text { UK }\end{array}$}} & poor \\
\hline 622 & ST85/6416 (III) & ST85/6418 (NT) & $10^{-4}$ & & & & good \\
\hline 623 & ST85/7119 (I) & ST85/7125 (III) & $10^{-4}$ & & & & good \\
\hline 624 & ST84/5518 (III) & $1030 \quad$ (all) & $10^{-3}$ & & & & poor \\
\hline 625 & ST85/6288 (III) & ST85/8099 (I) & $10^{-3}$ & Thailand & & UK & good \\
\hline 626 & ST85/2077 (III) & ST85/2086 (III) & $5 \times 10^{-2}$ & \multirow{2}{*}{\multicolumn{3}{|c|}{$\begin{array}{l}\text { New Zealand } \\
\text { Italy }\end{array}$}} & moderate \\
\hline 627 & ST85/1772 (III) & ST85/1770 (III) & $5 \times 10^{-3}$ & & & & poor \\
\hline 628 & ST84/9549 (III) & $1030 \quad$ (all) & $5 \times 10^{-3}$ & S. Africa & & UK & poor \\
\hline 629 & ST85/6235 (NT) & ST85/6236 (NT) & $5 \times 10^{-4}$ & \multirow{2}{*}{\multicolumn{3}{|c|}{$\begin{array}{c}\text { Brazil } \\
\text { Denmark }\end{array}$}} & good \\
\hline 630 & ST85/8103 (81) & ST85/8101 (III) & $10^{-4}$ & & & & moderate \\
\hline 631 & ST85/2209 (I) & ST85/2218 (NT) & $10^{-5}$ & \multirow{4}{*}{\multicolumn{3}{|c|}{$\begin{array}{l}\text { U.S.A. } \\
\text { New Zealand } \\
\text { Hong Kong } \\
\text { Yugoslavia }\end{array}$}} & moderate \\
\hline 632 & ST85/2077 (III) & ST85/2086 (III) & $10^{-4}$ & & & & moderate \\
\hline 633 & ST85/2137 (III) & ST85/2146 (III) & $10^{-2}$ & & & & moderate \\
\hline 634 & ST85/5104 (III) & ST85/5105 (III) & $10^{-2}$ & & & & moderate \\
\hline
\end{tabular}

RTD $=$ Routine test dilution.

$\mathrm{NT}=$ Not typable by the international phages at 100RTD.

* International set of typing phages.

$\dagger$ Phages 616-626 were propagated in broth, the remainder in soft agar; phages 624, 626 and 634 were extremely difficult to propagate.

$¥$ Good stability: no loss of titre during storage for 6 months at $4^{\circ} \mathrm{C}$; moderate: reduction of titre by one log during storage for 6 months at $4^{\circ} \mathrm{C}$; poor: reduction of titre by 1-2 logs during storage for 6 months at $4^{\circ} \mathrm{C}$. 
Table II. Lytic spectra (host range) of the 19 experimental phages

\begin{tabular}{|c|c|c|c|c|c|c|c|c|c|c|c|c|c|c|c|c|c|c|c|}
\hline \multirow[b]{2}{*}{ Test strain } & \multicolumn{19}{|c|}{ Reaction with phage no. (serogroup) } \\
\hline & $\begin{array}{l}\widehat{\theta} \\
\frac{0}{0} \\
0\end{array}$ & $\begin{array}{l}\widehat{\theta} \\
\frac{\sigma}{0}\end{array}$ & $\begin{array}{l}\underset{5}{\infty} \\
\underset{0}{0}\end{array}$ & $\begin{array}{l}\mathbb{E} \\
\frac{a}{6}\end{array}$ & $\begin{array}{l}\text { I્ } \\
\text { 잉 }\end{array}$ & 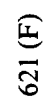 & $\underset{\widetilde{N}}{\overparen{\oplus}}$ & $\begin{array}{l}\text { త్ర } \\
\text { స్ }\end{array}$ & 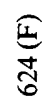 & $\begin{array}{l}\text { I્ } \\
\text { 气ુ }\end{array}$ & త్ర్ర & $\underset{\widehat{\widehat{C}}}{\widehat{\widehat{C}}}$ & $\begin{array}{l}\text { I્ } \\
\text { ్ָర }\end{array}$ & $\begin{array}{l}\text { క } \\
\text { స్రి }\end{array}$ & 周 & $\underset{\sqrt{6}}{\stackrel{E}{E}}$ & 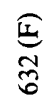 & 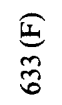 & 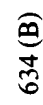 \\
\hline $3 \mathrm{~A}$ & 1 & 1 & - & - & - & - & 1 & 1 & - & - & - & - & - & 0 & - & - & - & - & - \\
\hline 3B & i & 1 & - & - & - & - & - & - & - & - & - & - & - & 0 & - & 1 & - & - & - \\
\hline $3 \mathrm{C}$ & - & - & - & 1 & - & - & 1 & 1 & - & - & - & - & 1 & 0 & - & - & _- & - & - \\
\hline 6 & 5 & 5 & 3 & 5 & 4 & 3 & 5 & 5 & - & 3 & 5 & 4 & - & 4 & 4 & 4 & 4 & 4 & 4 \\
\hline 7 & 5 & 5 & 3 & 5 & 4 & 3 & 5 & 5 & - & 3 & 5 & 4 & - & 4 & 4 & 4 & 4 & 4 & 4 \\
\hline 29 & - & - & - & - & - & - & - & 0 & - & - & - & - & - & 0 & - & - & - & - & - \\
\hline $29 \mathrm{~A}$ & - & - & - & - & - & - & - & 0 & - & 3 & - & 2 & - & 2 & 0 & 0 & - & - & - \\
\hline $31 / 44$ & 3 & 3 & 3 & 3 & 3 & 3 & 3 & 3 & - & 3 & 4 & 4 & - & 3 & 3 & 4 & - & 4 & - \\
\hline $42 B / 47 C$ & - & 2 & - & 1 & - & - & 3 & 2 & - & 1 & - & - & - & 0 & - & - & - & - & - \\
\hline $42 \mathrm{C}$ & 1 & 3 & 2 & - & 1 & - & 4 & 4 & - & 1 & 1 & 3 & 0 & 2 & 3 & 4 & - & - & - \\
\hline $42 \mathrm{E}$ & 3 & 2 & - & - & 1 & - & 2 & 4 & - & - & - & 2 & - & 0 & 3 & 3 & - & - & - \\
\hline $44 \mathrm{~A}$ & - & 3 & - & - & - & - & 1 & 3 & - & - & - & 0 & 0 & 0 & - & 4 & - & - & - \\
\hline 47 & 5 & 5 & 3 & 5 & 4 & 5 & 5 & 0 & - & - & 5 & 4 & - & 3 & 3 & 0 & - & 4 & 5 \\
\hline 47B & - & - & 1 & - & - & - & 1 & 1 & - & - & - & - & - & 2 & - & 2 & - & - & - \\
\hline 52 & - & - & 1 & - & - & - & - & 0 & - & - & - & - & - & 0 & - & - & - & - & - \\
\hline $52 \mathrm{~A} / 79$ & - & 0 & 1 & - & - & - & 3 & 0 & - & - & - & 4 & - & 3 & 3 & 0 & - & - & - \\
\hline & 0 & 4 & 3 & - & 3 & 0 & 4 & 4 & - & 3 & - & 4 & - & 3 & 3 & 2 & - & - & 0 \\
\hline 54 & 5 & 4 & 4 & 0 & 4 & 4 & 5 & 5 & - & 3 & 5 & 4 & - & 3 & 4 & 4 & - & 4 & 5 \\
\hline 55 & 1 & - & - & - & - & 0 & 1 & - & - & - & - & - & - & 0 & - & 2 & - & - & - \\
\hline 71 & - & 1 & - & - & - & - & 2 & - & - & - & - & - & - & 1 & - & 1 & - & - & - \\
\hline 75 & 0 & 0 & 4 & 0 & 3 & 4 & 0 & 0 & - & 3 & 4 & 4 & - & 3 & 3 & 4 & - & - & _ \\
\hline 77 & 0 & 4 & 0 & 0 & 3 & 0 & 4 & 0 & - & 3 & 4 & 4 & - & 2 & - & 0 & - & - & - \\
\hline 80 & - & 2 & - & - & - & - & 2 & 1 & - & - & - & - & - & 0 & - & - & - & - & - \\
\hline 81 & - & - & 1 & - & - & - & - & 0 & - & - & - & - & - & 0 & - & - & - & - & - \\
\hline $83 \mathrm{~A}$ & 5 & 5 & 3 & 1 & 4 & 5 & 5 & 0 & 3 & 3 & 5 & 4 & - & 2 & 5 & 4 & 3 & 5 & 5 \\
\hline $83 \mathrm{C}$ & - & - & 1 & - & - & - & - & 0 & - & - & - & 2 & - & 0 & - & 0 & - & - & - \\
\hline 84 & 4 & 4 & 3 & 0 & 4 & 0 & 4 & 3 & - & - & 5 & 4 & - & 0 & 4 & 0 & - & 0 & 5 \\
\hline 85 & 0 & 0 & 4 & 5 & 4 & 4 & 0 & 0 & - & - & 4 & 1 & 3 & 0 & 3 & 4 & 5 & 5 & - \\
\hline 88 & 0 & 5 & 4 & 0 & 4 & 0 & 5 & 0 & - & - & 5 & 4 & - & 0 & 4 & 0 & - & 0 & 5 \\
\hline 90 & 0 & 5 & 3 & 0 & 4 & 1 & 5 & 0 & - & - & 5 & 4 & - & 0 & 4 & 3 & - & 0 & 4 \\
\hline 94 & - & - & - & - & - & - & - & - & - & - & - & - & - & 0 & - & - & - & - & - \\
\hline 95 & - & 3 & 1 & - & - & - & 3 & 0 & - & - & - & 2 & - & 0 & 1 & - & - & - & - \\
\hline 96 & - & - & - & - & - & - & - & 2 & - & - & - & - & - & 1 & - & - & - & - & - \\
\hline 932 & 0 & 4 & 0 & - & - & - & 3 & 0 & - & 3 & - & 0 & - & 0 & - & 0 & - & - & - \\
\hline 2009 & 3 & - & 1 & - & - & - & 1 & 0 & - & 3 & - & 2 & - & 0 & - & - & - & - & - \\
\hline 8719 & - & - & - & - & - & - & - & 0 & - & - & - & - & - & 1 & - & - & - & - & - \\
\hline
\end{tabular}

* Reactions grades as detailed by Blair and Williams (1961);0 = inhibition, - = no reaction.

Reduction in host range may, therefore, be a result of propagation in this strain.

One strain, ST85/2077 carried two distinct phages; the large-plaque phage was named CRF 626, the small-plaque phage CRF 632. Four phages - 619, 621,624 and 628 - were very unstable on storage at $4{ }^{\circ} \mathrm{C}$; with six other phages-626, 630 , $631,632,633$ and 634 - there was a tenfold reduction in titre after storage for 6 months at $4^{\circ} \mathrm{C}$.
Activity of the phages on the test strains

The activity of the 19 phages against the 547 methicillin-sensitive strains is given in table III; 173 strains were typable by these phages, 115 strongly (at least one ++ reaction). The majority of typable strains (90) belonged to phage groups III or I + III. The lack of activity of these phages on strains of phage groups II and V was expected 
Table III. Activity of the experimental phages on 547 methicillin-sensitive strains

\begin{tabular}{|c|c|c|c|c|c|c|c|c|}
\hline \multirow{2}{*}{$\begin{array}{l}\text { Reaction with } \\
\text { experimental } \\
\text { phages }\end{array}$} & \multicolumn{8}{|c|}{$\begin{array}{c}\text { Number of strains with given reaction } \\
\text { in phage group }\end{array}$} \\
\hline & I & II & III & $\mathrm{I}+\mathrm{III}$ & $\mathrm{V}^{*}$ & Misc $\dagger$ & NT & Total \\
\hline $\begin{array}{l}\text { Strongly typable } \\
\text { No + + reaction } \\
\text { NT }\end{array}$ & $\begin{array}{r}18 \\
5 \\
56\end{array}$ & $\begin{array}{r}0 \\
0 \\
69\end{array}$ & $\begin{array}{l}46 \\
19 \\
53\end{array}$ & $\begin{array}{l}44 \\
24 \\
19\end{array}$ & $\begin{array}{r}0 \\
2 \\
74\end{array}$ & $\begin{array}{r}3 \\
4 \\
27\end{array}$ & $\begin{array}{r}4 \\
4 \\
76\end{array}$ & $\begin{array}{r}115 \\
58 \\
374\end{array}$ \\
\hline Total & 79 & 69 & 118 & 87 & 76 & 34 & 84 & 547 \\
\hline
\end{tabular}

NT= non-typable.

* Lytic group V, 94 and 96 (Porthouse 1984).

$\dagger$ Misc $=95$ or 81 alone.

because strains of these phage groups are rarely methicillin-resistant. Of the 23 typable group-I strains, 15 were lysed by phage CRF 625 alone. Two miscellaneous strains lysed by phage 81 were also lysed only by phage CRF 625 . Although the other phages were group-III related, it is likely that phage 625 is more closely related to the phages of group I. All 160 isolates of the EMRSA were phage group-III related. Of the 213 other methicillinresistant strains, 67 were phage group-III or I+ III related and a further 63 strains were lysed by groupI phages. It is not surprising, therefore, that typability of the epidemic isolates was $100 \%(95.6 \%$ strongly) and that more than half $(55.4 \%, 47 \%$ strongly) of the other British, methicillin-resistant strains were typable by these phages.

\section{Activity of individual phages}

The figure shows lysis by individual phages, expressed as a percentage of: all typable strains, methicillin-sensitive strains, isolates of the Thames EMRSA, and other British, methicillin-resistant strains. For each histogram, the phages selected originally for their ability to lyse the Thames strain, i.e., nos. 616, 618, 620, 621, 622, 627, 630 and 634, are to the left. The most active phages were nos. $616,621,622,627,630,634,617$ and 626, all of which lysed $>50 \%$ of typable strains. An excess of activity of these phages could be seen on the other methicillin-resistant strains. Phages 623 and 625 acted relatively more frequently on methicillinsensitive strains. The activity of phage 625 within the methicillin-sensitive strains was, however, almost completely confined to strains of phage group I. Reactions with phages 623 and 625 were found in composite patterns within the other methicillin-resistant strains, as were reactions with phages 629,631 and 633 . The activity of phages
618,620 and 632 was spread through all groups of strains, but strong lysis by these phages was found more often in isolates of the epidemic strain, usually those with the primary phage type $84 / 85 \pm / 88 \mathrm{~A} /$ 932. Phages $619,624,628$ and 631 reacted infrequently and weakly. The reactions of phages 621 , 627,632 and 633 were almost always weak. These eight phages, and phage 634, which was unstable and difficult to propagate, were excluded from any further set.

\section{Lysis of the Thames EMRSA}

A constant pattern of lysis by phages 616,621 , $622,627,630,634,617$ and 626 was identified for isolates of the epidemic strain. Phage 626 had been selected as inactive on the Thames strain, but the parent strain contained two phages and so the activity of phage 626 on the epidemic strain may have been masked. Phage 617 was derived from an isolate of the Thames strain and had been modified by propagation on strain NCTC 8325 . No activity of phage 623 and only a few, weak reactions of phages 625 and 629 on isolates of the Thames strain were recorded.

\section{Reduction of the phage set}

After inspection of the activities of the phages, and taking into consideration ease of propagation and stability, it was decided that 10 phages - 616 , $617,618,620,622,623,625,626,629$ and $630-$ might be used to distinguish isolates of methicillinresistant strains of $S$. aureus which did not derive from the Thames strain from those that did. A copositivity matrix (Pether, 1968) was constructed for the reactions of the ten selected phages at a ++ level on the non-Thames strains of methicillinresistant $S$. aureus included in the test series (table IV). 


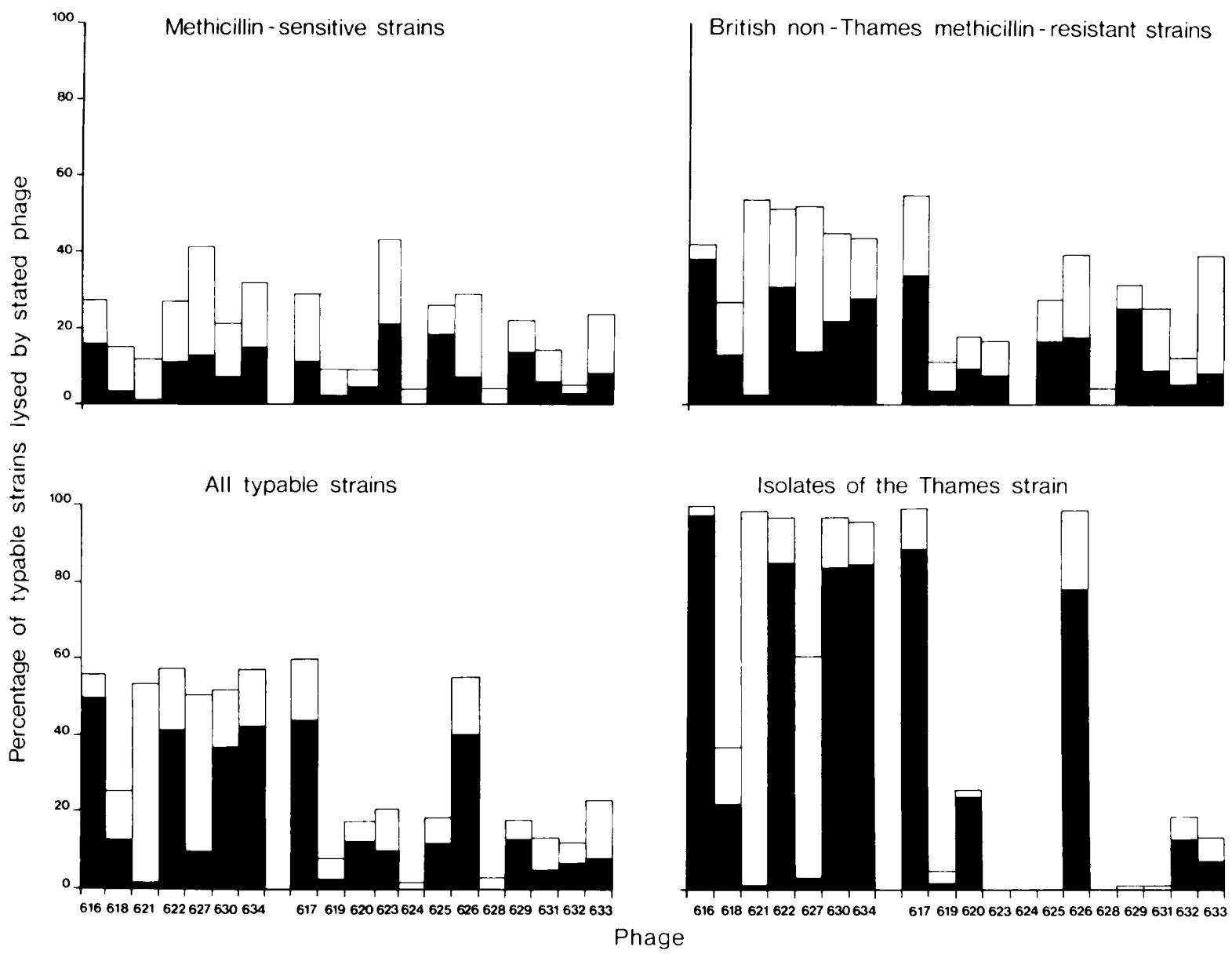

Figure. Percentage of typable strains lysed by individual phages. The shaded area indicates strong reactions. Phages selected because they lysed the Thames strain are to the left.

Table IV. Matrix showing the frequency of co-lysis between pairs of phages tested with 213 other methicillin-resistant $S$. aureus strains lysed strongly by selected experimental phages

\begin{tabular}{|c|c|c|c|c|c|c|c|c|c|c|}
\hline & 616 & 617 & 618 & 620 & 622 & 623 & 625 & 626 & 629 & 630 \\
\hline 616 & & $69 \cdot 1^{*}$ & $21 \cdot 8$ & $18 \cdot 2$ & $58 \cdot 2$ & $9 \cdot 1$ & 0 & $45 \cdot 5$ & $9 \cdot 1$ & 45.5 \\
\hline 617 & $77 \cdot 6^{*}$ & & $20 \cdot 4$ & $22 \cdot 4$ & $79 \cdot 6$ & $8 \cdot 2$ & $14 \cdot 3$ & $53 \cdot 1$ & $14 \cdot 3$ & $51 \cdot 0$ \\
\hline 618 & $66 \cdot 7$ & $55 \cdot 6$ & $\ldots$ & $61 \cdot 1$ & $50 \cdot 0$ & $5 \cdot 6$ & $16 \cdot 7$ & 38.9 & $11 \cdot 1$ & $33 \cdot 3$ \\
\hline 620 & 76.9 & 84.6 & $84 \cdot 6$ & $\ldots$ & $69 \cdot 2$ & $7 \cdot 7$ & 0 & $15 \cdot 4$ & 0 & $46 \cdot 2$ \\
\hline 622 & $72 \cdot 7$ & 88.6 & $20 \cdot 5$ & $20 \cdot 5$ & $\ldots$ & $4 \cdot 5$ & $18 \cdot 2$ & $54 \cdot 5$ & $18 \cdot 2$ & $52 \cdot 3$ \\
\hline 623 & $45 \cdot 5$ & $36 \cdot 4$ & $9 \cdot 1$ & $9 \cdot 1$ & $18 \cdot 2$ & $\ldots$ & $36 \cdot 7$ & 0 & $72 \cdot 7$ & $36 \cdot 4$ \\
\hline 625 & 0 & $29 \cdot 2$ & $12 \cdot 5$ & 0 & $33 \cdot 3$ & $16 \cdot 7$ & $\ldots$ & 0 & $83 \cdot 3$ & $12 \cdot 5$ \\
\hline 626 & $96 \cdot 2$ & 100 & 26.9 & $9 \cdot 1$ & $92 \cdot 3$ & 0 & 0 & $\ldots$ & 3.8 & $69 \cdot 2$ \\
\hline 629 & $13 \cdot 5$ & 18.9 & $5 \cdot 4$ & 0 & $21 \cdot 6$ & $21 \cdot 8$ & $54 \cdot 1$ & $2 \cdot 9$ & $\ldots$ & $10 \cdot 8$ \\
\hline 630 & $80 \cdot 6$ & $80 \cdot 6$ & $19 \cdot 3$ & $22 \cdot 6$ & $74 \cdot 2$ & $12 \cdot 9$ & 9.7 & $58 \cdot 1$ & $12 \cdot 1$ & $\ldots$ \\
\hline $\begin{array}{l}\text { Total number of } \\
\text { strains lysed strongly }\end{array}$ & 55 & 49 & 18 & 13 & 44 & 11 & 24 & 26 & 31 & 31 \\
\hline
\end{tabular}

* Of the strains lysed strongly by phage $616,69 \cdot 1 \%$ were also lysed strongly by phage 617 , the total number of strong reactions of phage 616 being used as the divisor; similarly of the strains lysed strongly by phage $617,77.6 \%$ were also lysed strongly by phage 616 , the total of strong reactions by phage 617 being used as divisor; calculations done similarly for other pairs of phages at $++(50$ or more plaques) level. 
Table V. Activity of five selected experimental phages on 145 typable strains of methicillin-resistant $S$. aureus not of the Thames strain.

\begin{tabular}{|c|c|c|c|c|c|c|}
\hline \multirow{2}{*}{$\begin{array}{l}\text { Phage } \\
\text { no. }\end{array}$} & \multicolumn{6}{|c|}{$\begin{array}{c}\text { Matrix of co-lysis at any level } \\
\text { with phage no. }\end{array}$} \\
\hline & 616 & 617 & 622 & 626 & 630 & $\mathrm{p}$ \\
\hline 616 & $41 \cdot 4^{*}$ & $75 \cdot 0$ & $73 \cdot 3$ & $66 \cdot 7$ & $75 \cdot 0$ & $0.11 \dagger$ \\
\hline 617 & 56.9 & 54.5 & 84.8 & $63 \cdot 3$ & $62 \cdot 0$ & $0 \cdot 10$ \\
\hline 622 & 59.5 & 90.5 & 51.0 & $63 \cdot 5$ & 63.5 & $0 \cdot 11$ \\
\hline 626 & $70 \cdot 2$ & 81.7 & 82.5 & 39.3 & 68.4 & 0.14 \\
\hline \multirow[t]{2}{*}{630} & $60 \cdot 0$ & $65 \cdot 3$ & $62 \cdot 7$ & $52 \cdot 0$ & $44 \cdot 8$ & 0.06 \\
\hline & & & & \multicolumn{2}{|c|}{ Average probability } & $0 \cdot 10$ \\
\hline
\end{tabular}

*The $616 / 616$ cell is the percentage of typable strains lysed by that phage; similarly for other phages

$\dagger$ Probability of any strain having the pattern $616 / 617 / 622 / 626 / 630$ if phage 616 is active on it; similarly for other phages.

\section{Analysis of typing patterns and discrimination of the phage set}

Inspection of this matrix indicated that the activity of three phages-623, 625 and 629 - was unrelated to that of the other seven phages. The percentages of strains lysed by pairs of the phages $616,617,618,620,622,626$ and 630 depended, to some degree, on which phage was considered first. For example, 25 of the 55 strains $(45 \cdot 5 \%)$ lysed strongly by phage 616 were also lysed by phage 630 , but because only 31 strains in total were lysed strongly by phage 630 , the co-positivity when phage 630 was considered first was $80.6 \%$.

Isolates of the Thames EMRSA had patterns of lysis with the ten phages of $616 / 617 / 622 / 626 / 630$, when the primary type was $85 \pm / 88 \mathrm{~A} / 932$, and $616 /$ $617 / 618 / 620 / 622 / 626 / 630$, when the primary type was $84 / 85 \pm / 88 \mathrm{~A} / 932$. These seven phages are also relatively active on strains other than the Thames EMRSA so it was considered that this pattern may be found in unrelated British methicillin-resistant S. aureus.

This hypothesis was tested by two analyses. (1) The probabilities were calculated that an isolate of the Thames strain would react with phages $616 /$ $617 / 622 / 626 / 630$ at (a) any level and (b) strongly, and these figures were compared with those for strains of other, British, methicillin-resistant $S$. aureus by calculating the four co-positivity matrices, and, taking each phage in turn as first phage, calculating the possibilities of (a) and (b). An example of a calculation is given in table V. The four overall probabilities were obtained by averaging the individual probability calculations. (2) A microcomputer was programmed to select, from a file containing the experimental types of 180 of the 213 strains of other (non-Thames) methicillinresistant $S$. aureus, the strains which reacted (a) at any level, and (b) strongly, with the five phages$616 / 617 / 622 / 626 / 630$ - common to both experimental types of the epidemic strain.

In analysis (1), when isolates of the epidemic strain were considered there was a probability of 0.95 that any isolate of this strain would be lysed by all of the five phages, 616,617,622, 626 and 630, at any level, and a probability of 0.64 that all these reactions would be at the ++ level.

On testing the hypothesis by analysis (2), 28 strains were selected when the conditions set were reactions with phages $616,617,622,626$ and 630 , at any level. If a strong reaction ( ++ or better) with phage 623,625 or 629 was taken as contraindicating that an isolate was of the Thames strain, four strains (one reacting with phage 625 , one with phage 623 and two with phages 623 and 629) were excluded. With the remaining 24 strains, inspection of the primary phage type left doubt about relationship to the Thames strain on only one occasion. When selection of similar strains was restricted to those reacting strongly with the five phages, the number of similar strains was reduced to 17 , including this one strain. Inspection of the primary data left doubt as to the status of this strain.

It appeared, therefore, that the activity of some of these phages was closely related, despite the diverse countries of origin and, although a pattern of lysis of isolates of the Thames EMRSA could be identified, this pattern was also found in apparently 
unrelated methicillin-resistant strains. However, when the complete phage-type of these strains was considered, the majority could be distinguished from the Thames strain.

\section{Discussion}

Strains of $S$. aureus are nearly always lysogenic, sometimes multiply so (Rountree, 1949; Rippon, 1954). Recently, studies of strains prevalent in parts of Australia (Vickery et al., 1982; Beard-Pegler and Vickery, 1985) have indicated that phages derived from clinical strains still have a place in the investigation of local problems. Unlike the Australian workers, we selected our phage-producing and -propagating strains from as wide an area as possible, and, by choosing propagating strains solely for their susceptibility to phage, attempted to make our experimental phage set as "different" as possible. It is clear from table III that we were not successful in this; 18 of our phages were lytic group-III related. One, phage 625 , was group-I related. This bias was intrinsic given the hospital origin of the strains from which the selection was made.

The international phage-typing set for $S$. aureus contains only two serological group-F phages, 77 and 84 , so the preponderance of phages of this serogroup in this supplementary phage set was somewhat unexpected. However, a brief literature survey (Rountree, 1949; Porthouse, 1984; BeardPegler and Vickery, 1985) suggested that phages of this serological group are not uncommon.

It was encouraging that phages included because of their ability to lyse a representative isolate of the Thames EMRSA retained this ability after purification by single plaque passage and propagation to high titre on a phage-sensitive strain. Two additional phages, 617, derived from an isolate of the Thames strain, and 626, also showed activity on isolates of this epidemic strain. Presumably, phage 617 had undergone considerable modification by propagation on strain NCTC 8325, which possesses active restriction modification systems and is multiply lysogenic (Rippon, 1956; Iordanescu and Surdeanu, 1976). Phage 626 was a large-plaque

\section{REFERENCES}

Ayliffe G A J et al. 1986 Guidelines for the control of epidemic methicillin-resistant Staphylococcus aureus. (Report of a combined working party of the Hospital Infection Society and the British Society for Antimicrobial Chemotherapy). Journal of Hospital Infection 7: 193-201.

Beard-Pegler M A, Vickery A M, 1985 Lysogenicity of methicillin-resistant strains of Staphylococcus aureus. Journal of Medical Microbiology 20 : 147-155. phage derived from the same strain as phage 632 ; the activity of a mixed phage preparation is never predictable.

The phages in this experimental set could, on their range of activity, be divided into two broad groups - those that tended to react with isolates of the epidemic strain and those that did not. The activity of phages within a group, however, remained associated when their activity on strains of other British, methicillin-resistant $S$. aureus was analysed. It would appear, therefore, that we developed a set of phages broadly belonging to group III, but within this set we have subgroups, one centring on 617 and one centring on 629 , whose activity is not closely related. Two phages, 624 and 628 , both propagated on strain 1030 , an extremely phage-susceptible strain, had so little activity that no conclusion except the inadvisability of using strain 1030 as a propagating strain, could be drawn for them.

An increase in relative activity of the phages non-reactive on the Thames strain could be seen when the typing results of other methicillinresistant and methicillin-susceptible strains were examined, but several strains in these two groups gave patterns of lysis similar to that of the epidemic strain. The results of co-positivity analysis (Pether, 1968) tended to confirm this somewhat pessimistic view; the pattern of lysis $616 / 617 / 622 / 626 / 630$ was found for $95 \%$ of the Thames isolates examined, but too many (about 10\%) of other methicillinresistant strains typable by this phage set, also gave this pattern of lysis. However when the phage types obtained with the experimental phages were used in conjunction with the primary types, most of these strains were clearly not the Thames strain. These phages, therefore, while providing a useful adjunct in the confirmation of the identity of individual isolates with the Thames strain, must not, by themselves, be used to define an isolate of this strain. Extended studies with a reduced set of these phages may help to clarify their usefulness.

For the period of this work, October and November 1985, N. C. was a W.H.O. Fellow at the Central Public Health Laboratory, Colindale.

Blair J E, Williams R E O 1961 Phage typing of staphylococci. Bulletin of the World Health Organization 24: 771-784.

de Saxe M J, Notley C M 1978 Experiences with the typing of coagulase-negative staphylococci and micrococci. Zentralblatt fur Bakteriologie, Parasitenkunde, InfektionsKrankenheiten und Hygiene 1 Abteilung Originale A. 241 : 4659.

Iordanescu S, Surdeanu M 1976 Two restriction and modification systems in Staphylococcus aureus NCTC 8325. Journal of General Microbiology 96: 277-281. 
Marples R R, Richardson J F, de Saxe M J 1986 Bacteriological characters of strains of Staphylococcus aureus submitted to a reference laboratory related to methicillin resistance. Journal of Hygiene 96 : 217-223.

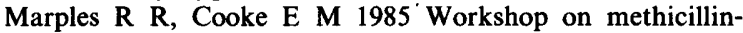
resistant Staphylococcus aureus held at the headquarters of the Public Health Laboratory Service on 8 January 1985. Journal of Hospital Infection 6: 342-348.

Novick R 1967 Properties of a cryptic high-frequency transducing phage in Staphylococcus aureus. Virology 33: 155-166.

Pether J V S 1968 An alternative method of phage-typing Staphylococcus aureus. Journal of Hygiene 66: 605-623.

Porthouse A 1984 Studies on a high-frequency transducing phage of Staphylococcus aureus. M.Sc. Dissertation. University of Surrey.

Rippon J E 1956 The classification of bacteriophages lysing staphylococci. Journal of Hygiene 54: 213-226.

Rountree P M 1949 The serological differentiation of staphylococcal bacteriophages. Journal of General Microbiology 3:164-173.

Swanstrom M, Adams M H 1951 Agar layer method for production of high titer phage stocks. Proceedings of the Society for Experimental Biology and Medicine 78: 372-375.

Vickery A M, Beard-Pegler M A, Rountree P M 1983 Strain differentiation in methicillin-resistant Staphylococcus aureus. Pathology 15: 235-40. 